\title{
The Pandora's Jar of problem vaccines and sub-standard drugs in Sri Lanka
}

Sri Lanka Journal of Child Health, 2009; 38: 113-114

(Key words: Problem vaccines, substandard drugs, Sri Lanka)

The immunisation programme of Sri Lanka has been a role model for many other countries, especially in our region. We have done virtually the impossible by ensuring a very high coverage rate of all vaccinations against many of the diseases that caused havoc in the not too distant past. It is the justifiable boast of many authorities in this country that we have even eradicated some of the dreaded infective diseases of the past. The immunisation programme has progressed without any glitches for many a decade and produced the sort of results that perhaps only dreams are made of.

Unfortunately, this happy position is now threatened by a series of mishaps that is likely to have a lasting impact on the immunisation status of the country. There have been several catastrophes in the recent past with regard to vaccines that were administered to children in Sri Lanka through the Expanded Immunisation Programme of The Ministry of Health. Some children have died while others have developed significant reactions. There have been Commissions of Inquiry into several of these calamities. Even foreign experts have been roped in to look at the problems. Inquiry reports have been filed.

At the outset, it must be emphasised that even a single death that is directly caused by a vaccine is just one death too many. No child should die as a result of a vaccine that is administered purely as a preventive measure. In a country that rightly boasts of the provision of free health care to every citizen of the country, it is a blot on the record of the free health service that such calamities do occur. Whichever way one looks at it, it is totally impossible to reconcile such a disaster with a service that is primarily designed to look after the health of its citizens.

To add to all its current and totally inexplicable woes, the Ministry of Health of Sri Lanka has been rocked in very recent times by the finding of substandard drugs as well. Contaminated phials of injections, some containing even splinters of glass within the sealed contents, have been found from a number of medical institutions to which these drugs have been supplied by the Ministry of Health. In clinical practice, drugs such as thyroxine have been found to be quite inadequate from a bio-availability profile. There are probably quite a number of other drugs that fall into this category of "unreliable potency" as well.

This entire saga seems to have opened a Pandora's jar of many an ill. When Pandora opened the jar given to her by Zeus, which is mistakenly referred to as a "box", she did it through curiosity". The bizarre events related to vaccines and drugs have opened a redoubtable jar which appears to be filled to capacity with the proverbial ills, toils and sicknesses. This time round, the jar has been opened by the uncanny events that are crying out for attention in this country.

There seems to be something seriously wrong with the procedures adopted to license these vaccines and drugs for importation into this country. It is claimed by the authorities that these preparations were sanctioned by expert committees of authoritative medical personnel including even renowned academics. However, it must be pointed out that these experts would have been bound by the administrative regulations governing purchases in the state sector. One such archaic rule is that the preparation should be the cheapest one of all the products of that type submitted for the tender. This is a ridiculous piece of the sort of administrative requirement that is not even worth the paper it is written on. In the case of vaccines and drugs, the cost should not be the only criterion taken into account for initial assessment of the tender. It is also not certain whether proper quality testing data including bio-availability details are supplied to the evaluators. Certainly, it is quite doubtful whether independent testing of the material supplied for the tender is undertaken and perhaps more relevantly, whether any random testing of imported batches of vaccines and drugs is employed once the manufacturer has been given the licence to supply the drugs to the state sector. Admittedly, our country is not in possession of the infrastructure required for such rigorous testing of the thousands of medications that are imported through the National Health Service. In such a scenario, one has no option other than to utilise the facilities available in other friendly countries to secure such a process of quality control. 
This journal is not interested in finding scapegoats to apportion blame for the current situation. It is only concerned with preventing such terrible tragedies occurring in the future. Lessons have to be learnt from some of the ways in which successful immunisation programmes in other countries, including the West, have been torpedoed and scuttled by some actual or imagined untoward effects following vaccinations. That is the last thing we need in this country.

It must be pointed out that countless numbers of immunisations are done in the private sector using vaccines every day right round the country. The type of vaccine problems seen in the state sector have not been seen in the private sector. The only difference is that in the private sector, only vaccines from reputed manufacturers with a proven track record are used.
At the very bottom of Pandora's jar was a thing called hope. It was the only good thing that emanated from that quaint piece of Greek mythology. We too would hope very much that sanity would prevail and that the health of our nation would not be jeopardised and tampered with by ill conceived and short sighted legislative import requirements and inadequate evaluation of the vaccines and drugs imported into this country.

\section{Dr. B J C Perera}

Joint Editor.

\section{References}

1. Pandora's Box. Available from: http://en.wikipedia.org/wiki/Pandora's box Accessed 2nd November 2009. 